Open Access

\title{
Heavy duty gas turbine monitoring based on adaptive neuro-fuzzy inference system: speed and exhaust temperature control
}

Nadji Hadroug ${ }^{1}$, Ahmed Hafaifa ${ }^{1 *}$, Mouloud Guemana ${ }^{2}$, Abdellah Kouzou' ${ }^{1}$, Abudura Salam² and Ahmed Chaibet ${ }^{3}$

\author{
* Correspondence: \\ hafaifa.ahmed.dz@ieee.org \\ ${ }^{1}$ Applied Automation and Industrial \\ Diagnostics Laboratory, Faculty of \\ Science and Technology, University \\ of Djelfa, 17000 Djelfa, DZ, Algeria \\ Full list of author information is \\ available at the end of the article
}

\begin{abstract}
Gas turbines are currently a popular power generation technology in countries with access to natural gas resources. However they are very complex systems the operation of which at peak performance is challenging. This paper proposes the use of a hybrid approach based on an Adaptive Neuro-Fuzzy Inference System (ANFIS) for the control of the speed and the exhaust temperature of a gas turbine. The main aim is to maintain turbine operation at optimum performance. The results obtained, based on the use of the Rowen model, clearly show the effectiveness of the proposed hybrid speed/exhaust temperature control approach for the gas turbine.
\end{abstract}

Keywords: Adaptive neuro-fuzzy inference system (ANFIS), Gas turbine, Exploitation data, Exhaust temperature, Rowen model, Heavy duty gas turbine (HDGT), Hybrid learning

\section{Background}

In recent years, gas turbines have become important and widespread devices for heavy industrial applications including electrical power generation and service in the oil and gas industries. Keeping these turbines operating at optimal efficiency is an important research question for the manufacturer and operator of these devices. Turbines are very complex systems that require advanced control techniques to ensure the proper control of their operating parameters. Of particular interest is the control of the speed and the exhaust temperature. Note that the control of the exhaust temperature is affected by ambient environmental parameters.

Recently several studies have been performed to ensure the modelling and the control of gas turbine. Benyounes et al. have proposed a fuzzy logic approach to modelling and controlling vibrations in gas turbines used for pipeline gas transportation [1, 2]. Balamurugan et al. have studied the control of the load frequency of an operating gas turbine plant based on signal processing analysis, via both large and small signal models [3]. Asgari et al. introduced the Nonlinear Autoregressive Exogeneous (NARX) model for the simulation of single shaft gas turbine startup operation [4]. Zaidan et al. have proposed a prognostics system to predict gas turbine behavior using a Bayesian hierarchical model based on a variational approach [5]. Zhu et al. developed a mathematical model to study steam turbine operation phases based on an optimization

(c) The Author(s). 2017 Open Access This article is distributed under the terms of the Creative Commons Attribution 4.0 International License (http://creativecommons.org/licenses/by/4.0/), which permits unrestricted use, distribution, and reproduction in any medium, provided you give appropriate credit to the original author(s) and the source, provide a link to the Creative Commons license, and indicate if changes were made. 
approach [6] and Onabanjo et al. have modelled the degradation of gas turbine components [7].

The development of gas turbine control systems is important in the oil and gas industries, where turbines are used both in power generation and pipeline gas transportation plants [2, 8-17]. In this context an adaptive neuro-fuzzy inference system (ANFIS)- based hybrid control approach is proposed in this paper. The main objective of the ANFIS control is to ensure the proper control of the speed and the exhaust temperature of a gas turbine based on the Rowen model [18]. It is important to note that the control system proposed in this paper is able to cope with changes in environmental parameters such as ambient temperature, not only by reducing the controlled parameter errors, but also by improving the quality of the response time and reducing the maximum overshoot of the proposed control system.

In 1983 Rowen developed a model of a heavy duty gas turbine plant based on a transfer function block diagram. His main idea was to build a simulation model to aid in the control of three main parameters of the gas turbine: the speed, the exhaust temperature, and the acceleration. Rowen succeeded in validating the system gains using coefficients and time constants estimated for his model based on test and field experience accumulated from numerous installations for many different applications [6]. The decisions taken during the control of a gas turbine profoundly impact the operating cost of the installation. The gas turbine system is a complex nonlinear system featuring strong interactions between operating variables, so it is important to account for the impact of monitoring system behavior on the system behavior. For this reason traditional approaches to turbine control are less effective at ensuring the required, reliable, level of control of parameter dynamic behavior.In this study, a dynamical analysis of the control of a representative gas turbine is carried out based on real operating conditions. The proposed neuro-fuzzy control approach is implemented by combining a neural network approach and a fuzzy systems approach in a homogeneous architecture. This paper demonstrates that the proposed hybrid approach improves the control of both speed and gas exhaust temperature for the gas turbine considered.

\section{Case description}

Several models have been developed in many applications for the control of the dynamic behavior of gas turbines. However, the complexity of the dynamic behavior of the gas turbine systems increases the difficulty of obtaining a reliable monitoring system for such devices.

This paper proposes the use of the adaptive neuro-fuzzy inference system (ANFIS) approach to ensure the control of the speed and the exhaust temperature of a gas turbine based on Rowen model [18], in order to maintain its optimum performance.

\section{Gas turbine modeling}

The present paper deals with a double shaft heavy duty gas turbine (HDGT) composed of two parts: the double-shaft rotor and the fuel control system. The fuel control system has four main functions: speed control, temperature control, throttle control, and the control of max (upper) and min (lower) fuel limits. The speed control mechanism is suitable for static applications or isochronous (time invariant) controls, and works 
sufficiently well over some dynamic speed range. The representation of the HDGT studied here is based on the Rowen model [6]. In the Rowen model the control system is based on three typical control loops: a speed control loop, a temperature control loop, and an acceleration control loop $[9,11-13,18]$. The main data of a representative HDGT turbine studied here are assembled in Table 1.

The proposed control configuration is shown in Fig. 1. The closed loop strategy allows the system performance to be optimized at a nominal operating point of the representative turbine $[19,12]$. The real process (blue curve) and the theoretical process (red curve) of the T-S diagram are presented in Fig. 2.

When the post-compression temperature inside the compressor follows an isentropic process, this temperature, at the nominal operating point, can be calculated as follows:

$$
T_{2 s(o c)}=T_{1(o c)} \times Z_{a(o c)}=300.3 \times\left(11.3 \times \frac{537.3}{539}\right)^{0.285}=598.81 \mathrm{~K}=325.81^{\circ} \mathrm{C}
$$

The index denoted by $\mathrm{s}$ corresponds to variables for the theoretical isentropic process, the index "oc" describes variables measured at operating conditions. $T_{1(o c)}$ presents the ambient temperature at the operating conditions in kelvin (K), $T_{2 s(o c)}$ presents the theoretical inside compressor temperature and $Z_{a(o c)}$ is a factor used to simplify calculations related to the operating conditions. This factor is defined as:

$$
Z a_{(o c)}=\left(P_{R} \times \frac{\dot{m}_{t}}{\dot{m}_{n}}\right)^{\frac{\gamma_{a}-1}{\gamma_{a}}}
$$

where: $\gamma_{a}$ is the specific heat ratio which is defined as $\gamma_{a}=C_{p a} /\left(C_{P a}-0.287\right)=1.4, C_{p a}$ is the specific heat at constant air pressure $\left(C_{p a}=1.015\right), P_{R}=11.3$ is the compressor pressure ratio which is given in Table $2 . \dot{m}_{t}=537.3 \mathrm{~kg} / \mathrm{s}$ is the typical exhaust mass flow and $\dot{m}_{n}=539 \mathrm{~kg} / \mathrm{s}$ is the nominal exhaust mass flow.

The real inside compressor temperature $T_{2}$ can be calculated as follows:

$$
T_{2}=T_{1}\left(1+\frac{Z_{a}-1}{\eta_{c}^{c}}\right)=598.7 K
$$

Here, $T_{1}$ is the real ambient temperature and $\eta_{c}$ is the efficiency of the compressor which can be calculated as follows:

$$
\eta_{c}=\frac{T_{2 s(o c)}-T_{1}}{T_{2(o c)}-T_{1}}=\frac{325.81-27.3}{401.54-27.3}=0.79
$$

and

Table 1 The data of heavy duty gas turbines

\begin{tabular}{ll}
\hline The metric Units & \\
\hline Model & $7001 \mathrm{~B}$ \\
The speed of turbine & $3000 \mathrm{rpm}$ \\
Nominal-Temperature & $510^{\circ} \mathrm{C}$ \\
Max torque & $16.231 \mathrm{Kg} \cdot \mathrm{M}$ \\
Inertia & $7.834 \mathrm{Kg} \cdot \mathrm{M} 2$ \\
Power Rating & $157.7 \mathrm{MW}$ \\
\hline
\end{tabular}




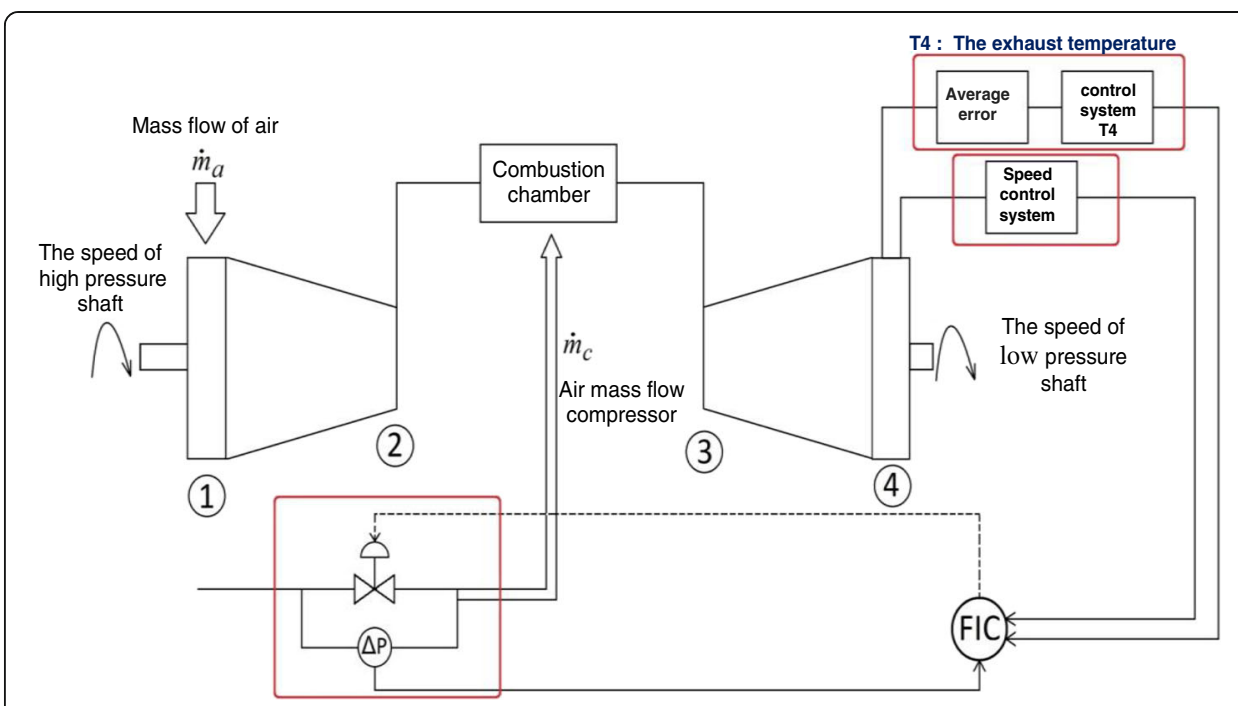

Fig. 1 Control setting of different subsystem of the TITAN 130 turbine

$$
Z_{a}=P_{R}^{\left(\frac{\gamma_{a}-1}{\gamma_{a}}\right)}=11.3^{\left(\frac{1.4-1}{1.4}\right)}=2
$$

When the turbine temperature follows an isentropic process, the theoretical exhaust temperature of the gas turbine (HP) section at the operating conditions can be calculated as follows:

$$
T_{4 s(o c)}=\frac{T_{3(o c)}}{Z_{g(o c)}}=\frac{1333}{\left(11.3 \times \frac{537.3}{539}\right)^{0.24}}=744.69 \mathrm{k}=471.69^{\circ} \mathrm{C}
$$

Here, $T_{3(o c)}$ is the combustion chamber temperature at the operating conditions and $Z_{a(o c)}$ is a factor used to simplify the calculations defined as:

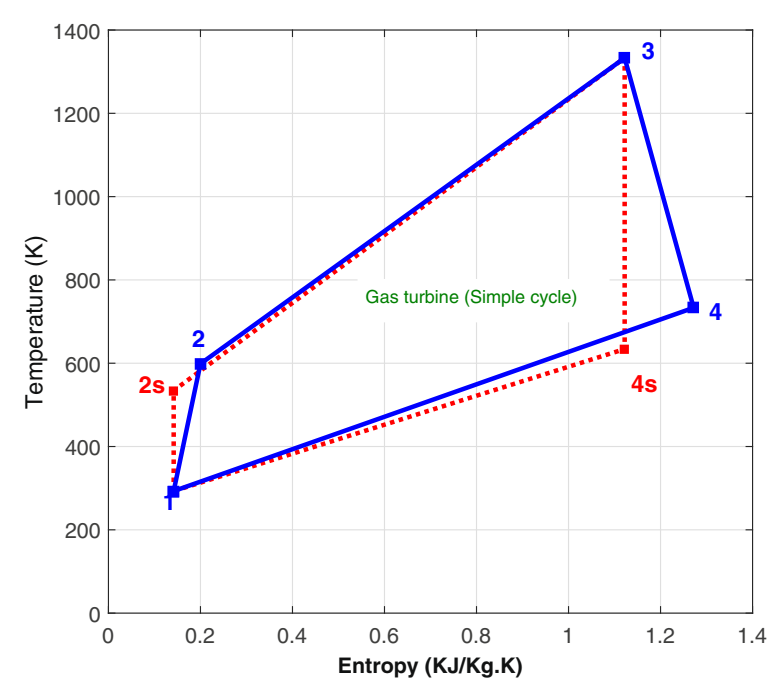

Fig. 2 T-S diagram of the real process in the studied gas turbine 
Table 2 Turbine parameters in nominal operating conditions [22]

\begin{tabular}{llll}
\hline Parameter & Symbol & Unit & Value \\
\hline Compressor pressure ratio & $\mathrm{PR}$ & $/$ & 11.3 \\
Fuel mass flow & $/$ & $\mathrm{kg} / \mathrm{s}$ & 9.1 \\
Lower heating value of fuel & $\mathrm{LHV}$ & $\mathrm{kJ} / \mathrm{kg}$ & 42,532 \\
Exhaust mass flow & $\dot{m}_{n}$ & $\mathrm{~kg} / \mathrm{s}$ & 539 \\
Exhaust temperature & $\mathrm{TR}$ & ${ }^{\circ} \mathrm{C}$ & 510 \\
Nominal frequency & $\mathrm{F}$ & $\mathrm{Hz}$ & $50-60$ \\
Electrical power & $P_{G n}$ & $\mathrm{MW}$ & 157.7 \\
The inside compressor temperature & $T_{2(0 c)}$ & ${ }^{\circ} \mathrm{C}$ & 401.54 \\
Efficiency (simple cycle) & $\eta$ & $\%$ & 34.7 \\
Turbine speed & $\mathrm{N}$ & $\mathrm{rpm}$ & 3000 \\
\hline
\end{tabular}

$$
Z g_{(o c)}=\left(P_{R} \times \frac{\dot{m}_{t}}{\dot{m}_{n}}\right)^{\frac{\gamma_{g}-1}{\gamma_{g}}}
$$

The real exhaust temperature of the gas turbine will be very high and it is calculated as follows:

$$
T_{4}=T_{3}\left(1-\eta_{t}\left(1-\frac{1}{Z_{g}}\right)\right)=770.55 k=497.56^{\circ} \mathrm{C}
$$

Where $T_{3}$ is the combustion chamber temperature, $T_{4}$ is the temperature of the exhaust gas of the gas turbine (HP) section and $\gamma_{g}=1.333$ is the specific heat ratio of the gas.

with: $\eta_{t}=\frac{T_{3}-T_{4(o c)}}{T_{3}-T_{4 s(o c)}}=\frac{1060-510}{1060-471.69}=0.935$ and $Z_{g}=R^{\left(\frac{\gamma_{g}-1}{\gamma_{g}}\right)}=11.3^{\left(\frac{1.33-1}{1.33}\right)}=1.824$.

The compressor input power is given by the following equation:

$$
\text { Power }=\dot{m} \times C_{p a}\left(T_{2}-T_{1}\right)
$$

Where $\dot{m}_{a}$ is the air mass flow, $\dot{m}_{g}$ is the gas mass flow, $C_{p g}$ is the specific heat at constant gas pressure, $C_{p a}$ is the specific heat at constant air pressure, with $C_{p a}=1.015$ and $C_{p g}=1.149$.

And the output power of high pressure turbine $\mathrm{HP}$ is given by the following expression:

$$
\text { Power }=\dot{m} \times C_{p g}\left(T_{3}-T_{4}\right)
$$

The torque per unit of the generated mechanical power of the studied gas turbine is presented as follows:

$$
P_{G}=\dot{m} \times\left[C_{p g}\left(T_{3}-T_{4}\right)-C_{p a}\left(T_{2}-T_{1}\right)\right]
$$

The Rowen model assumes a linear relationship with rotational speed within a velocity band from $95 \%$ to $107 \%$ of the nominal speed. In this region the unitary output power is calculated with: 


$$
\begin{aligned}
P_{G P \cdot U} & =\frac{P_{G n}(\text { calculated mechanical power })}{P_{G n}(\text { Electrical power })} \\
P_{G P \cdot U} & =\frac{\dot{m}_{n} \times\left[C_{p g}\left(T_{3}-T_{4}\right)-C_{p a}\left(T_{2}-T_{1}\right)\right]}{P_{G n}(\text { Electrical power })}
\end{aligned}
$$

So based on eqs. (1), (3) and (10), the output power output per unit can be calculated as follows:

$$
P_{G P \cdot U}=\frac{\dot{m}_{n} \times T 1\left\{\left(1-\frac{1}{Z_{g}}\right) C_{p g} \cdot \eta_{t}\left[1+\left(\frac{Z_{a}-1}{\eta_{c}}\right)\right]-C_{p a}\left(\frac{Z_{a}-1}{\eta_{c}}\right)\right\}+\eta_{c o m b} \cdot \eta_{t} H \cdot \dot{m}_{f n}(t)\left(1-\frac{1}{Z_{g}}\right)}{P_{G n}(\text { Electrical power })}
$$

with

$$
\dot{m}_{f n}(t)=\dot{m}_{f n} \cdot \dot{m}_{f p \cdot u}
$$

Finally, the output power per unit is given as:

$$
P_{G P \cdot U}=A+B \cdot \dot{m}_{f p \cdot u}
$$

The turbine parameters are calculated for nominal operating conditions according to Table 2.

It is obvious that when the HDGT is operating at nominal speed, the output torque (p.u) and the mechanical power (PG) are almost the same $(A=-0.223 ; \quad B=1.221$; $\dot{m}_{f n}=5.129 \mathrm{~kg} / \mathrm{s}$.

\section{Fuel valve positioner system modeling}

The valve positioner in the HDGT moves the actuator to a valve position which corresponds to the reference position value. The principle of the studied gas turbine valve positioner is shown in Fig. 3.

Based the Rowen model, the fuel flow equations are expressed as follows:

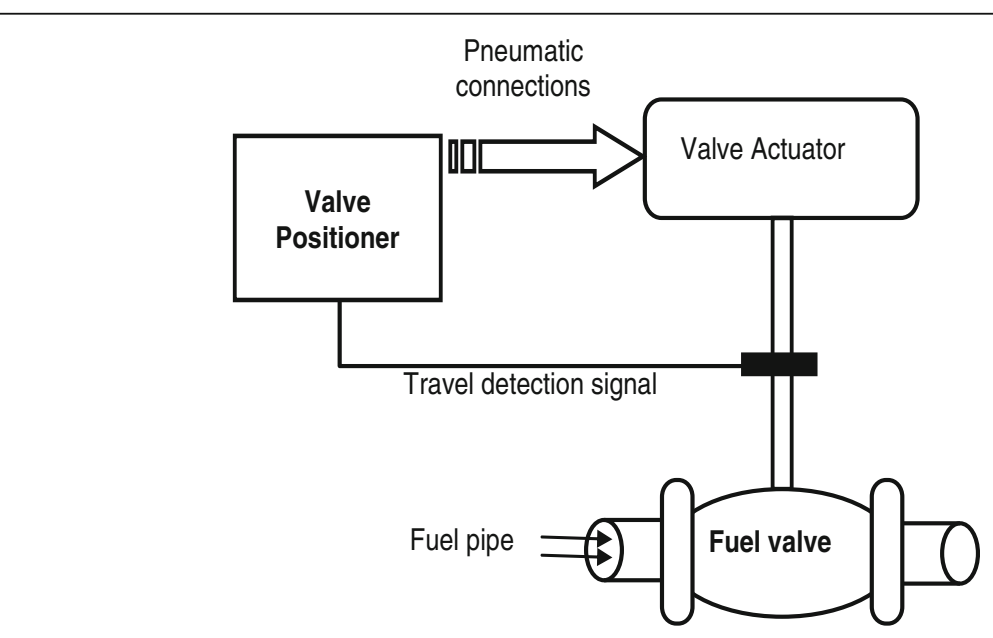

Fig. 3 The valve positioner of the studied HDGT 


$$
\dot{W}_{f}=\frac{K_{3} P v-W_{f}}{t_{3}}
$$

Here, $P v$ is the fuel per unit consumed in the combustion chamber, given by the expression:

$$
\dot{P} v=-\frac{1}{t_{2}} P v+\frac{\left(1-K_{N L}\right) K_{2}}{t_{2}} V_{C E}+\frac{K_{2}}{t_{2}} K_{N L}-\frac{K_{2} K_{4}}{t 2} W_{f}
$$

This representation facilitates the modeling of the studied gas turbine system, it allows a direct processing of the control variables of the HDGT, with a reliable configuration system, as shown in Figs. 4 and 5. The differential equations of the associated gas turbine, written in the Laplace transform domain, can be expressed as follows:

$$
S\left[\begin{array}{l}
P v(s) \\
W_{f}(s)
\end{array}\right]=\left[\begin{array}{cc}
-\frac{1}{t_{2}} & -\frac{K_{2} K_{4}}{t_{2}} \\
\frac{K_{3}}{t_{3}} & -\frac{1}{t_{3}}
\end{array}\right]\left[\begin{array}{l}
P v(s) \\
W_{f}(s)
\end{array}\right]+\left[\begin{array}{ll}
\frac{\left(1-K_{N L}\right)}{t_{2}} & \frac{K_{2}}{t_{2}} \\
0 & 0
\end{array}\right]\left[\begin{array}{l}
V_{C E} \\
K_{N L}
\end{array}\right]
$$

Where;

$$
\left\{\begin{array}{l}
s . p(s) \text { is the Labplace transform of } \frac{d p(t)}{d t}=\dot{p}(t) \\
s . w_{f}(s) \text { is the Labplace transform of } \frac{d w_{f}(t)}{d t}=\dot{w}_{f}(t)
\end{array}\right.
$$

$p(t)$ and $w_{f}(t)$ are functions of $(t)$ (i.e., functions of time domain), $p(s)$ and $w_{f}(s)$ are functions of $(s)$ (i.e., functions of frequency domain).

The PID controller is used to ensure the control of the installed gas turbine in oil and gas plants, where they are used to ensure the most important gas turbine parameters, especially speed and exhaust temperature, remain within desired bounds. While PID controllers are very simple, they are based on system linearization and so suffer from the major drawback of being non robust for nonlinear systems, with the control constants $\mathrm{Ki}, \mathrm{Kp}$, and $\mathrm{Kd}$ changing dramatically as process parameters change. To overcome this drawback, the ANFIS technique suggested in this paper may easily and

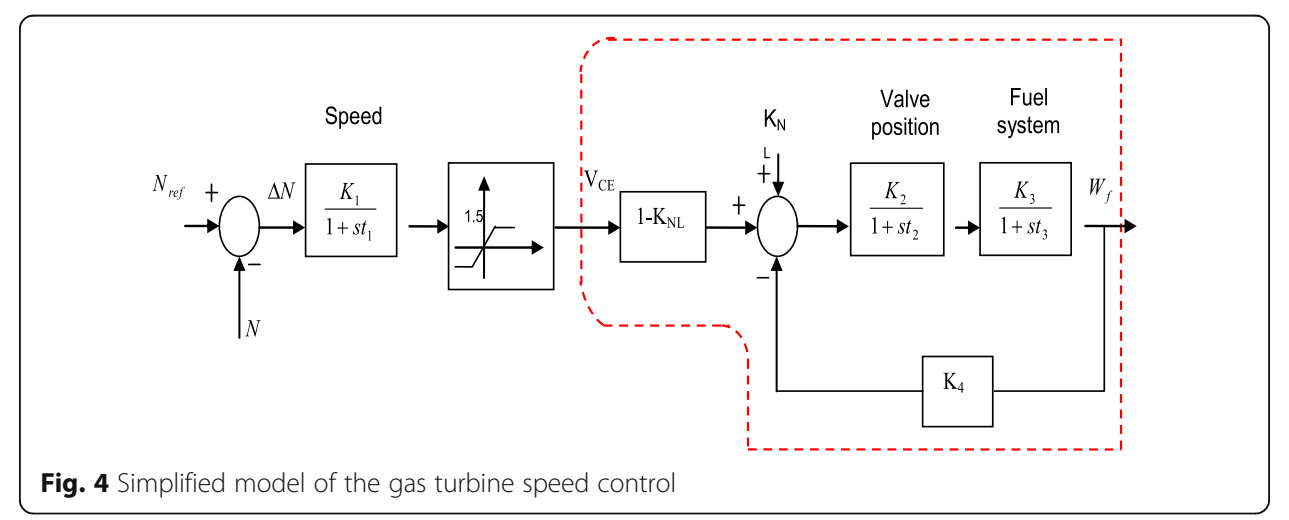




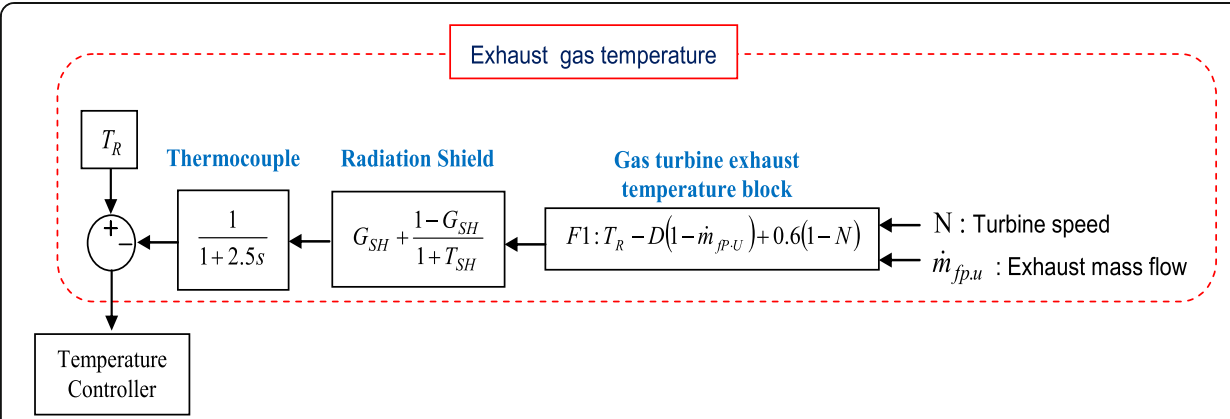

Fig. 5 Simplified model of the gas turbine temperature control

rapidly be updated as gas turbine parameters and ambient environmental variables change. The optimization considers the performance of the entire process.

\section{Adaptive neuro-fuzzy inference system (ANFIS)}

The principle of fuzzy approaches in the sense that the variables are not treated as logical variables but as linguistic variables close to human language. Furthermore, these linguistic variables are processed using rules that refer to some knowledge of the system behavior [18].

A whole series of fundamental concepts are developed in fuzzy logic. These concepts are used to justify and demonstrate the basic principles. The structure of a conventional fuzzy controller is shown in Fig. 6, it is composed of four separate blocks whose definitions are given below. The fuzzy controller is designed to automatically run a process based on a set by acting on the control variables, and it has some characteristics that are intrinsic advantages.

A rule-base (a set of IF-THEN rules) contains a fuzzy logic quantification of the linguistic description of the expert for how to achieve good control. An inference mechanism (also called "inference engine") emulates the interpretation and application of

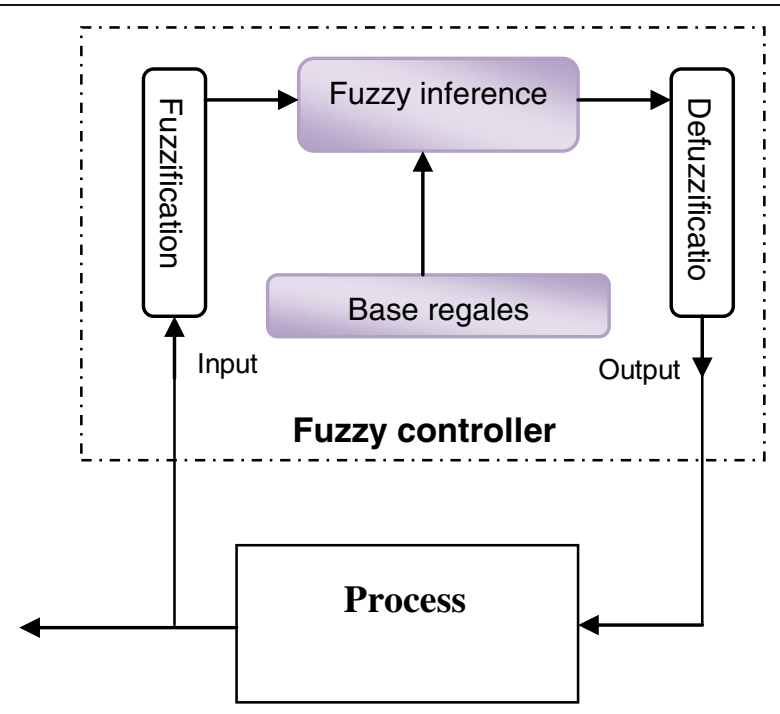

Fig. 6 Implementation of a fuzzy controller 
knowledge on how best to control the plant. A fuzzification interface converts the information into control signals for the inference mechanism which can be used to activate and apply rules. A defuzzification interface converts the results of the inference mechanism into the real process inputs. The rule-base is constructed so that a human expert is "in the loop." The information in the rules of the rule-base can come from a real human expert who has spent a long time learning the best way to control the process. The fuzzification process plays an important role in the relationship between the soft information that can be objective or subjective.

In this work, the adaptive neuro-fuzzy inference system (ANFIS) approach is used for the speed and the exhaust temperature control of the gas turbine, where an automatic model for the fuzzy rule generation is use. This mode is based on the inference model of Takagi Sugeno which was proposed by JSR Jang on 1993 [6]. Indeed, the ANFIS approach has attracted more industrial attention and it has been applied in several industrial applications $[6,7,12-18,20,21]$. Based on the ANFIS structure is used to ensure the control of the gas turbine instead of the classical controllers. The ANFIS approach is now well known and as it was well explained in detail in the previous works, it is basically composed of five neuronal layers that refine the fuzzy rules established by human experts and adjust the overlap between fuzzy sets, to describe the input-output behavior of the presented gas turbine system [6, 7, 12-18, 20,21]. On the other side, to use the basic architecture of ANFIS model a fuzzy inference system of Sugeno first order type is considered and two input linguistic variables $x_{1}$ and $x_{2}$ and one output $y$ are supposed. Furthermore, the basic rules are assumed to be of two broad types:

$$
\begin{aligned}
& \mathrm{R} 1: \text { If } x_{1} \text { is } A_{1} \text { and } x_{2} \text { is } B_{1} \text { Then } y_{1}=f_{1}(x, y)=p_{1} x+q_{1} y+r_{1} \\
& \mathrm{R} 2: \text { If } x_{1} \text { is } A_{2} \text { and } x_{2} \text { is } B_{2} \text { Then } y_{2}=f_{2}(x, y)=p_{2} x+q_{2} y+r_{2}
\end{aligned}
$$

Where $x_{1}$ and $x_{2}$ are the inputs, $A_{1}$ and $B_{2}$ are the fuzzy sets, $y_{1}$ and $y_{2}$ are the outputs of all defuzzification of neurons, $p_{i}, r_{i}$ and $q_{i}$ are the parameters of the $i^{\text {th }}$ rule determined during the learning process.

The structure of the proposed adaptive neuro-fuzzy network is shown in Fig. 7.

The outputs of the first layer are presenting the degrees of membership of the input variables $x_{1}$ and $x_{2}$ :

$$
O_{i}{ }^{1}=\mu_{A_{i}}(x) ; i=1,2
$$

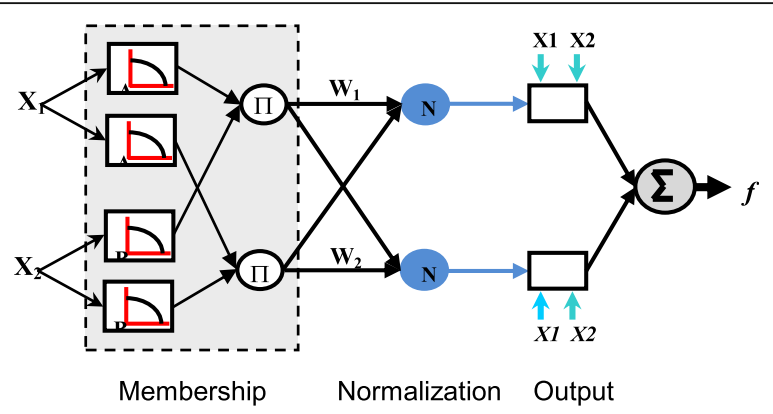

Fig. 7 Proposed adaptive neuro-fuzzy network structure 
Table 3 The two passes in the hybrid learning

\begin{tabular}{lll}
\hline & Forward Pass & Backward Pass \\
\hline Premise Parameters & Fixed & Back-propagation \\
Consequent Parameters & Least Squares Estimate & fixed \\
\hline
\end{tabular}

Each node in the second layer is a fixed type node denoted by " $\Pi$ " and their output generate the product (AND operator of fuzzy logic) of its inputs, that correspond to the degree of the relevant rule membership, presented as follows:

$$
O_{i}{ }^{2}=w_{i}=\mu_{A i}(x) \times \mu_{B i}(x) ; i=1,2
$$

Each node in third layer is a fixed type and it carries out the normalization of the weights of the fuzzy rules, given by:

$$
O_{i}^{3}=\overline{w_{i}}=\frac{w_{i}}{w_{1}+w_{2}} ; i=1,2
$$

In the fourth layer, each node is adaptive and calculates the outputs of the rules by performing the following function:

$$
O_{i}^{4}=\bar{w}_{i} \times f_{i}=\bar{w}_{i}\left(p_{i} x+q_{i} y+r_{i}\right) ; i=1,2
$$

The fifth layer comprises a single neuron providing the output ANFIS by calculating the sum of the outputs of the previous layer. Its output which is also presenting the network output is determined by the following relationship:

$$
O_{i}^{5}=f=\sum_{i} \bar{w}_{i} \times f_{i}
$$

On the other side, the ANFIS system learning is made from a set of data identification of the premises and consequences parameters of the fuzzy system, where the network structure is fixed. To achieve this phase of ANFIS system learning, a gradient descent algorithm with a least squares estimation using a hybrid learning rule is proposed as shown in Table 3. Hence, the following expression is obtained:

$$
f=\bar{W}_{1} f_{1}+\bar{W}_{2} f_{2}
$$

Table 4 Dynamic model parameters

\begin{tabular}{lc}
\hline Parameter & Value \\
\hline Radiation shield parameter $\quad G_{S H}$ & 0.85 \\
Radiation shield time constant $\quad T_{S H}$ & $12.2 \mathrm{~s}$ \\
Exhaust Temperature & $537.3^{\circ} \mathrm{C}$ \\
Fuel Demand signal Max Limit $\left(\max _{N L}\right)$ & 1.5 \\
Fuel Demand signal Min Limit $\left(\min K_{N L}\right)$ & -1 \\
$K_{1}=25 ; K_{2}=K_{3}=1$ & \\
$F 1: T_{R}-D\left(1-\dot{m}_{f P . U}\right)+0.6(1-N)$ & \\
$F 2: A+B \cdot \dot{m}_{f p \cdot u}+0.5(1-N)$ & \\
$T I=15.64$ & \\
\hline
\end{tabular}




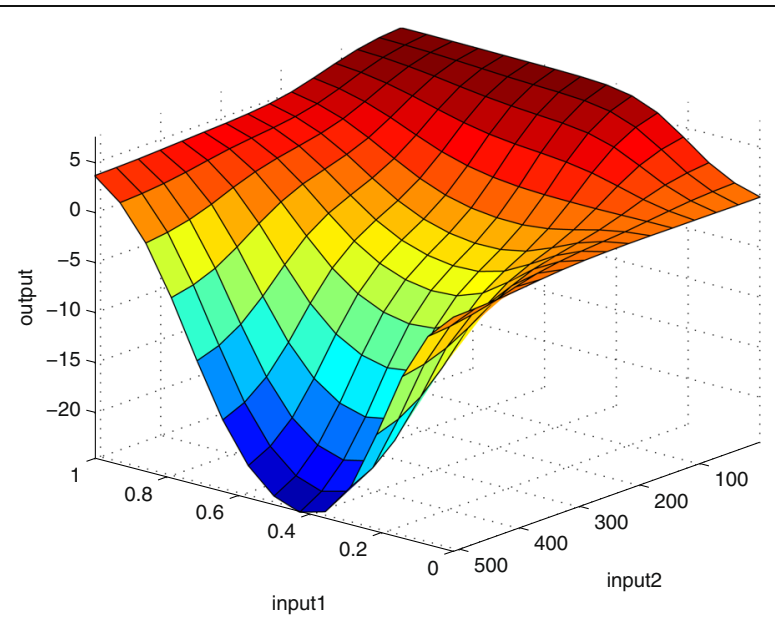

Fig. 8 Output area of the used ANFIS model

With $\left\{\begin{array}{l}f_{1}=p_{1} x_{1}+q_{1} x_{2}+r \\ f_{2}=p_{2} x_{1}+q_{2} x_{2}+r_{2}\end{array} \quad\right.$ and with a linear combination of consistent modifiable parameters $\left\{p_{1}, q_{1}, r_{1}, p_{2}, q_{2}, r_{2}\right\}$.Consequently:

$$
f=\left(\bar{W}_{1} x_{1}\right) \cdot p_{1}+\left(\bar{W}_{1} x_{2}\right) \cdot q_{1}+\bar{W}_{1} \cdot r_{1}+\left(\bar{W}_{2} x_{1}\right) \cdot p_{2}+\left(\bar{W}_{2} x_{2}\right) \cdot q_{2}+\bar{W}_{2} \cdot r_{2}
$$

Note that in this algorithm parameters corresponding both to the premises and of the consequences are optimized.

\section{Discussion and evaluation}

This work proposes the application of a hybrid approach based on an adaptive neurofuzzy inference system "ANFIS" to ensure the speed and the exhaust temperature control of a gas turbine 7001B. The control of the gas turbine system is performed in a closed loop, where the control type is isochronous, the system output and input data under normal operating conditions are used per unit of speed and temperature is based

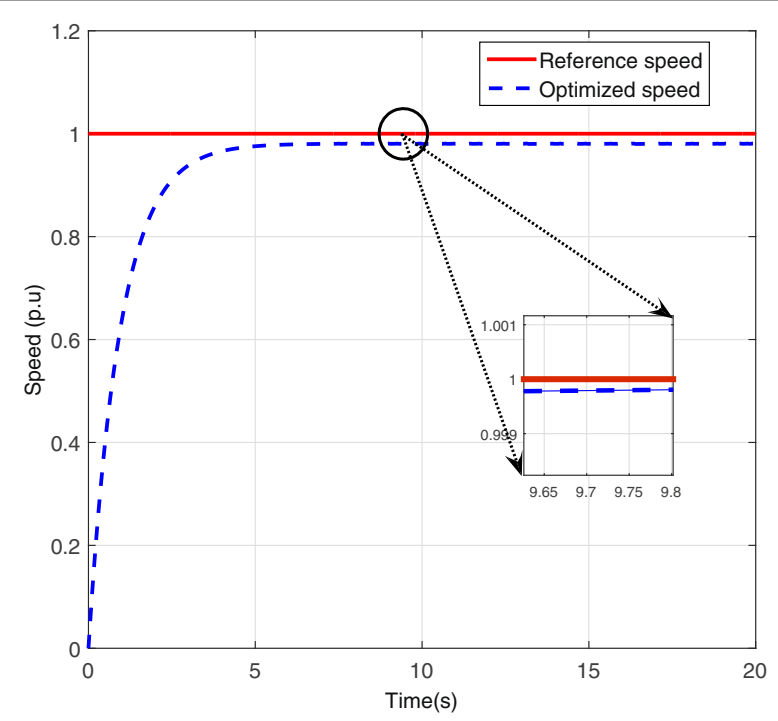

Fig. 9 Speed variation using Rowen model 


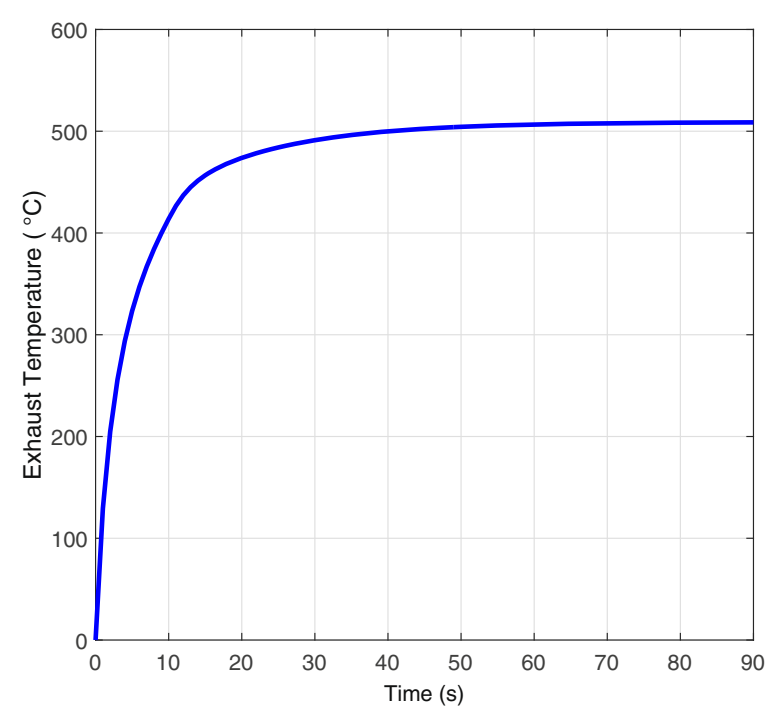

Fig. 10 Exhaust temperature variation using Rowen model

on the Rowen model for the HDGT we study. The parameters of this model are given in Table 4.

The following expressions are used to calculate the exhaust temperature and the torque of the gas turbine respectively:

$$
\begin{aligned}
& F 1: T_{R}-D\left(1-\dot{m}_{f P \cdot U}\right)+0.6(1-N) \\
& F 2: A+B \cdot \dot{m}_{f p \cdot u}+0.5(1-N)
\end{aligned}
$$

The proposed based ANFIS controller has two inputs (Tx error, error $\mathrm{n}$ ) and one output. Each input has three fuzzified fuzzy set of Gaussian types. Figure 8 shows the ANFIS controller surface of the studied gas turbine variables.

The obtained results of the high-efficiency gas turbine system control during startup using the ANFIS approach are shown in Figs. 9 and 10. Figure 9 shows the speed

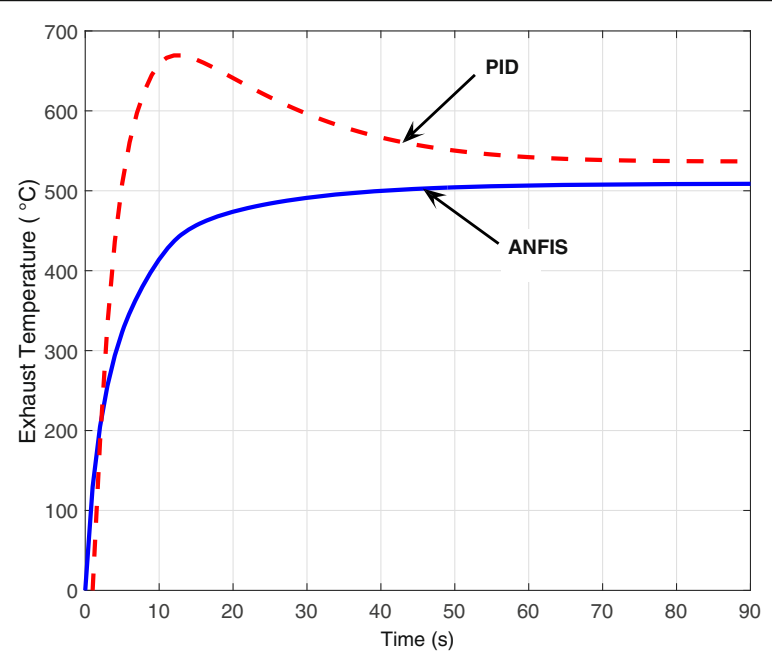

Fig. 11 Exhaust temperature response comparison between ANFIS and PID controllers 


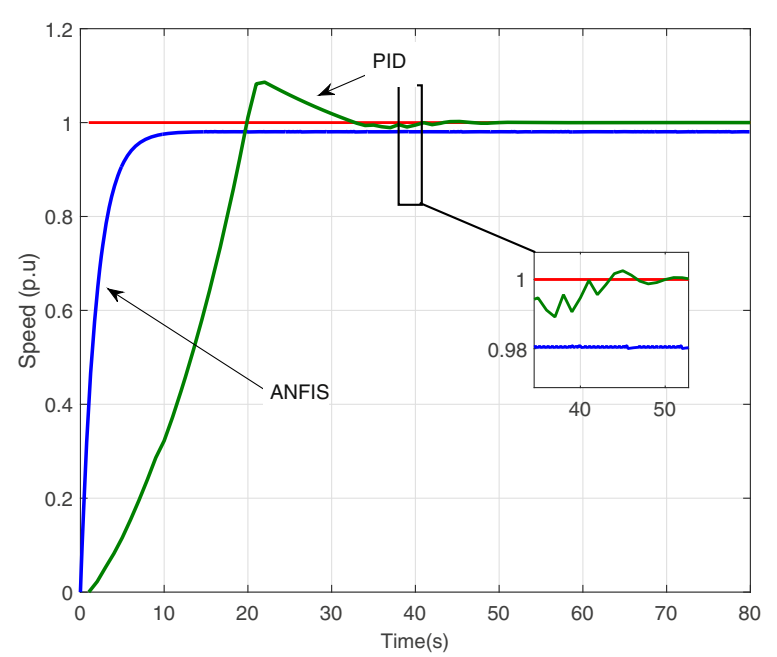

Fig. 12 Speed response comparison between ANFIS and PID controllers

variation per unit based on the Rowen model and Fig. 10 shows the measured exhaust temperature variation of the studied gas turbine.

In order to validate the ANFIS approach, a comparison with a PID controller has been performed for the both responses of the exhaust temperature and the speed as shown in Figs. 11 and 12 respectively. It is clear to see that, in both responses, the ANFIS controller responds more rapidly than does the PID controller. Indeed, the time response of the ANFIs is $5 \mathrm{~s}$, whereas the time response of the PID is $34 \mathrm{~s}$, which means that a gain of $29 \mathrm{~s}$ can be ensured by the use of the ANSIS controller. On the other hand the peak presented in the response of the PID controller response is avoided totally with the ANFIS controller. Therefore the ANFIS controller is more efficient and obtains a faster response time than the PID controller, suggesting that a reduced cost may be obtained when the ANFIS controller is used for complex industrial gas turbine systems.

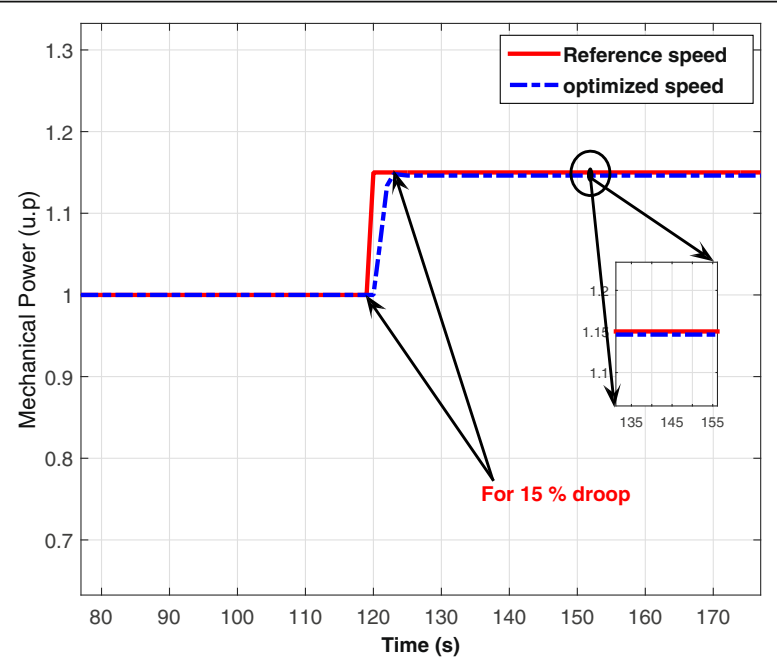

Fig. 13 Speed variation using Rowen model after speed step 15\% 


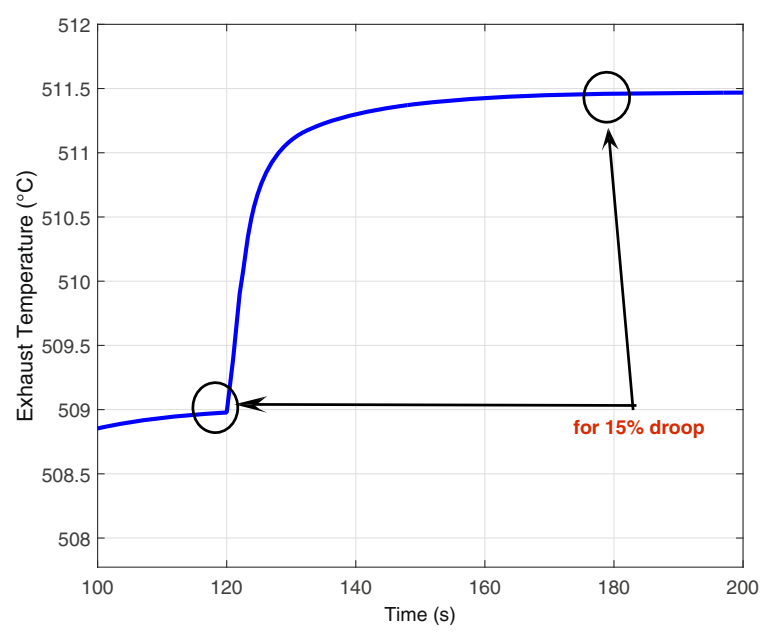

Fig. 14 Exhaust temperature after speed step 15\%

This improved response is achieved by imposing the desired performance by limiting the maximum overshoot value at around 15\% as shown in Figs. 13 and 14. From these two figures, it can be noted clearly that the proposed controller is working accurately with acceptable performances.

The results obtained in Figs. 13 and 14 describe the control of HDGT of $157.7 \mathrm{MW}$ type of the 7001B turbine model, based on the ANFIS approach using the Rowen model parameters reported in [18]. These results clearly show that the ANFIS controller achieves better performance for the control of the speed and the exhaust temperature of the gas turbine studies, which allows an efficiency improvement to be obtained for the entire system.

For this particular gas turbine, to understand the effect of the speed control on other gas turbine system parameters, simulations have been performed based on the use of a PID controlled to ensure the control of a Model 7001B gas turbine used in the present study. Indeed, two tests have been achieved using two distinct sets of PID controller parameters in order to check their impact on the controlled gas turbine parameters.

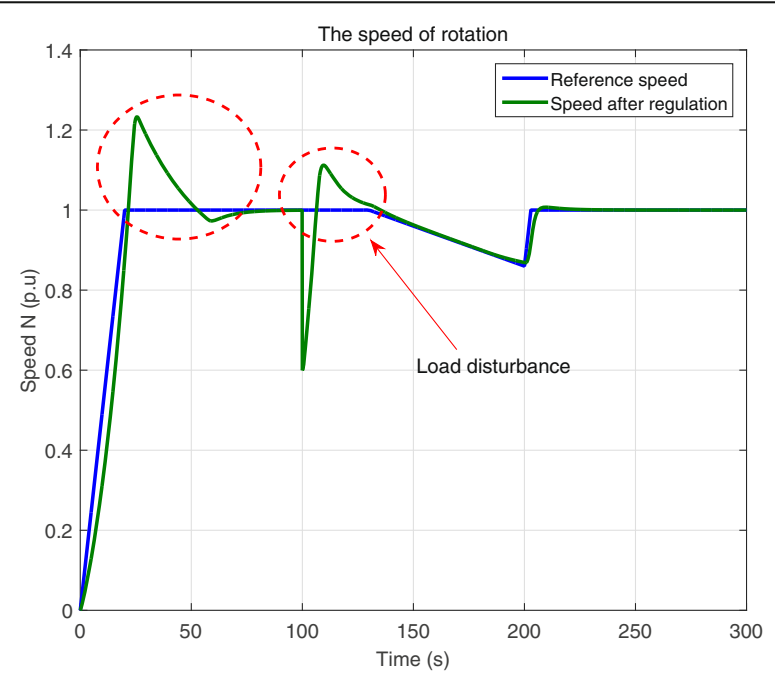

Fig. 15 Rotation speed of the gas turbine 


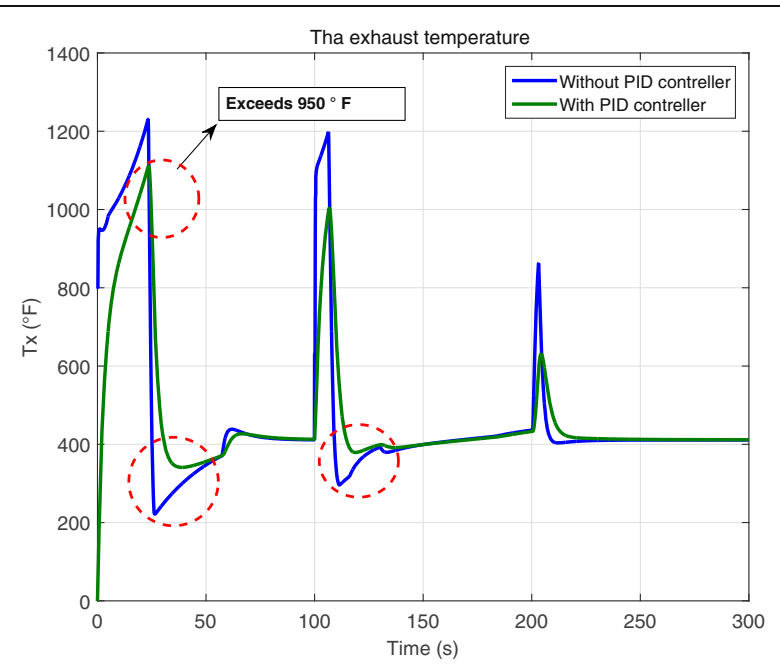

Fig. 16 Exhaust temperature of the gas turbine

The simulations results so obtained are shown in Figs. 15, 16, and 17 for test 01 and in Figs. 18, 19 and 20 for test 02 .

In this case, two factors affect the speed and the exhaust temperature of the gas turbine, as depicted in Figs. 15 and 16. The first factor is the change of the load at $t=100 \mathrm{~s}$ and the second factor is the linear decrease of the reference speed beginning at $t=130 \mathrm{~s}$ and ending $t=200 \mathrm{~s}$. Figure 15 makes it clear that the PID controller can control the gas turbine speed only very slowly at the initial transient peak around $t=30$ s when it returns to its reference value.

First test $01: K_{p}=10.5, \mathrm{Ki}=1, \mathrm{Kd}=1$

In this case, there are two factors that are affecting the speed and the exhaust temperature of the gas turbine as shown in Figs. 15 and 16, the first factor is the change of the load at $t=100 \mathrm{~s}$, and the second factor is the linear decrease of the

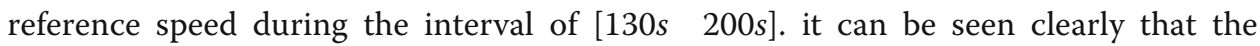

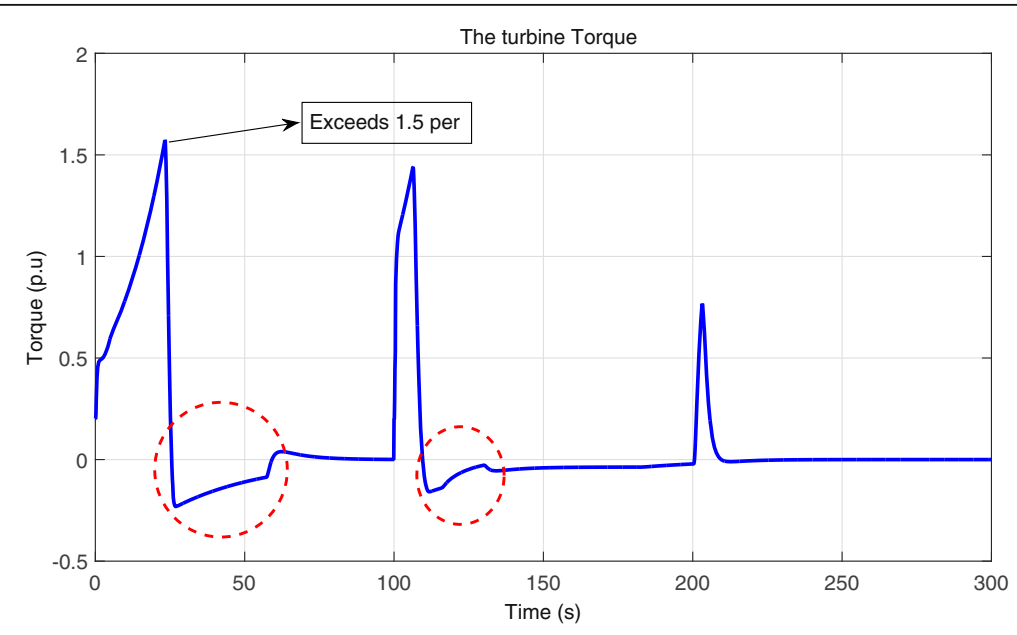

Fig. 17 Gas turbine torque 


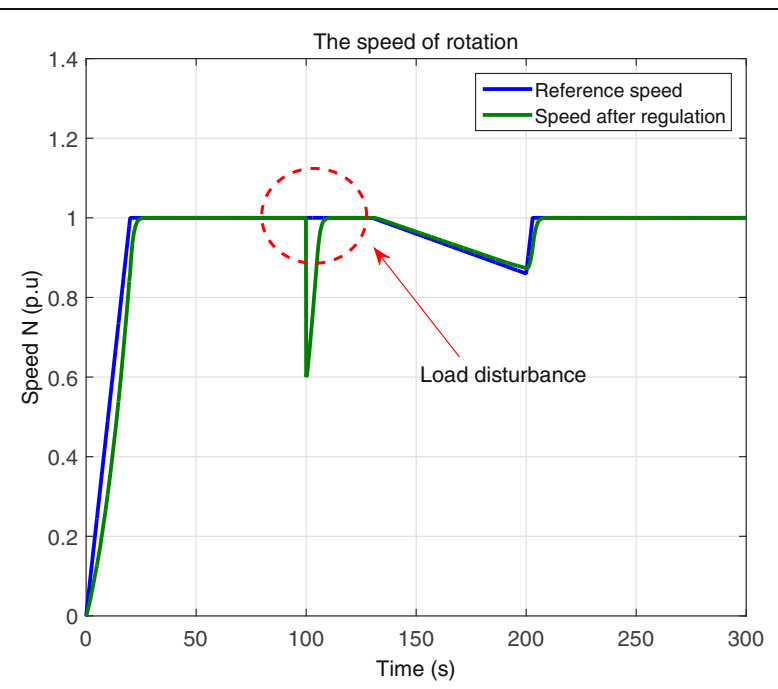

Fig. 18 Rotation speed of the gas turbine

PID controller can achieve the control of the gas turbine speed but slowly along 30 swhere it rejoins its reference value ( 1 p.u). Furthermore, Fig. 15 shows that an important overshoot of the developed speed over the reference speed, implying that control is not accurate. At the same time the control of the exhaust temperature is not accurately achieved, as an overshoot above the allowed limit of $960 \mathrm{~F}$ is observed. Such temperature overshoots can damage the turbine if they last for more than a very short time. However there is a difference between the responses with and without the use of the PID controller, as shown in Fig. 16. Figure 16 shows that the PID controller is not doing a good job, due to a poor choice of PID controller constants. The same outcome is visible in Fig. 17 for torque behavior dynamics. The perturbation in the system set point at $t=100$ is caused by the external operating constraints and between $t=130$ and $t=200$ is due to the air leakage at the compressor level.

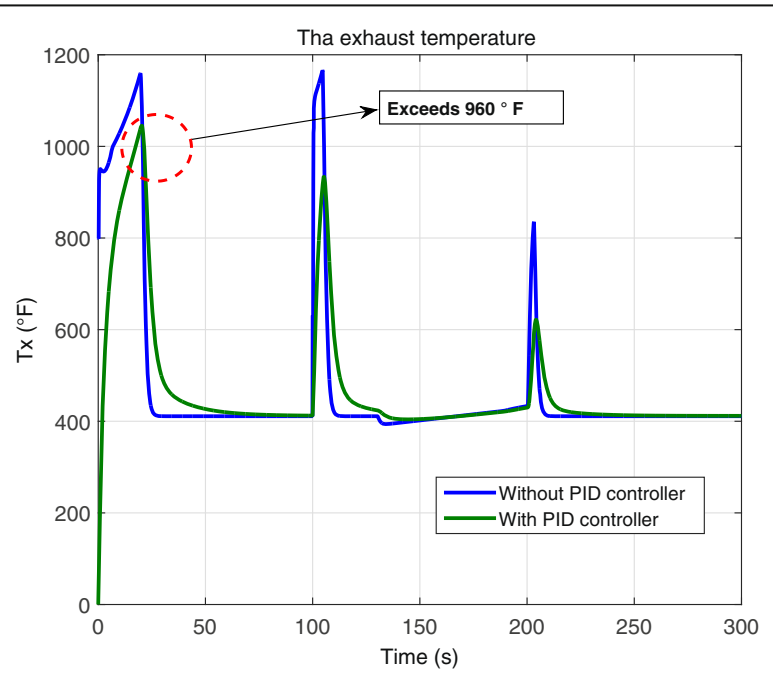

Fig. 19 Exhaust temperature of the gas turbine 


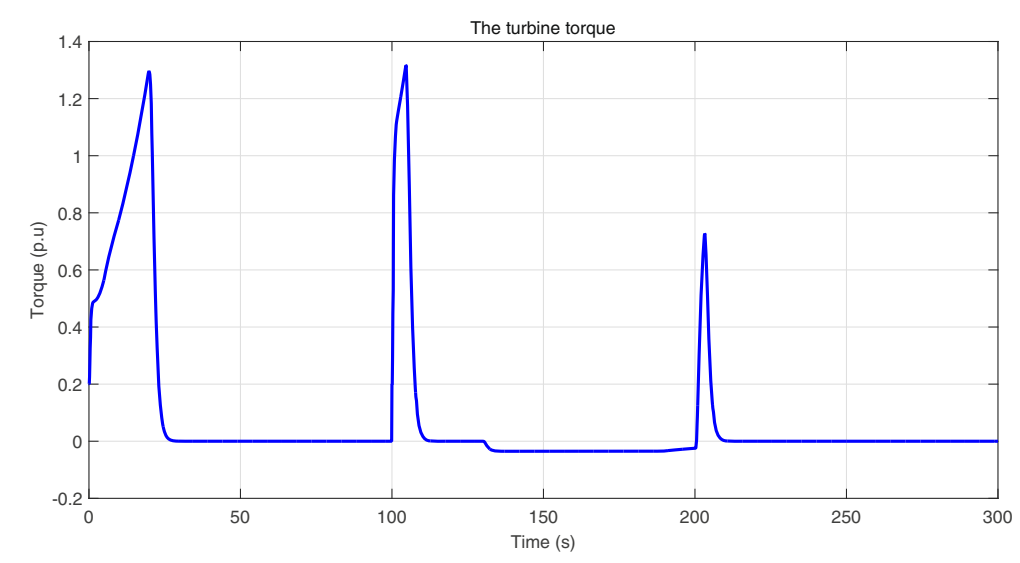

Fig. 20 Gas turbine torque

On the other hand, for a linear decrease in reference speed, the PID controller has better dynamics. It can be said the control is achieved and these results can be accepted as shown in Figs. 15, 16, and 17. For the start up operation of the turbine the PID controller has very results and presents a real danger as shown in Figs. 15, 16 and 17. Again, this can be explained by poor choice of PID parameters.

Second test 02: $K_{p}=10.5, \mathrm{Ki}=0, \mathrm{Kd}=0$

In this case, the same factors as in the first case are presented. Here there is a change of the load at $\mathrm{t}=100 \mathrm{~s}$ and a linear decrease of the reference speed during the time interval $[130 \mathrm{~s}, 200 \mathrm{~s}]$. Figure 18 makes it clear that the controller under the new parameters has achieved better control of the gas turbine speed when it rejoins its reference value of 1 per unit at $t=100 \mathrm{~s}$. At the same time the gas turbine develops excess torque to compensate for the drop in developed speed and to ensure stable operation

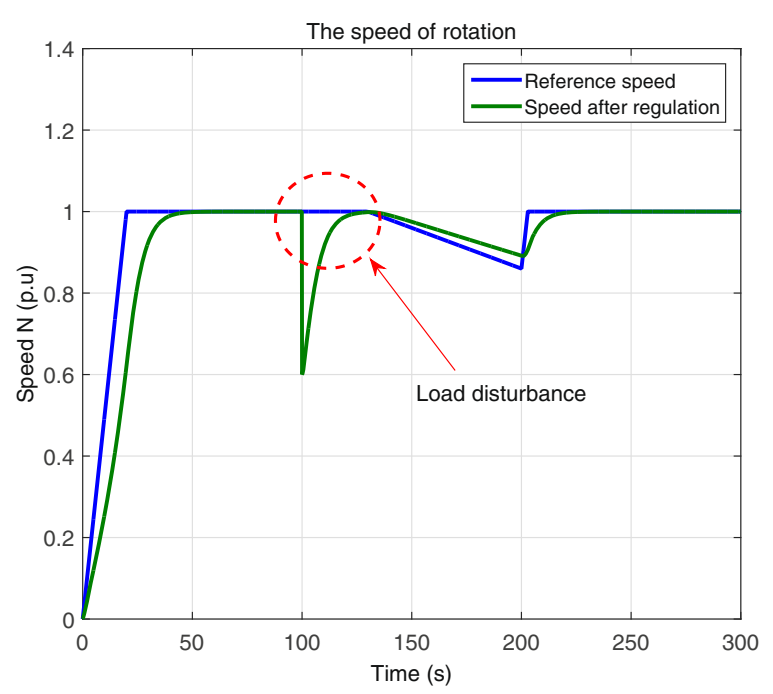

Fig. 21 Rotation speed of the gas turbine 


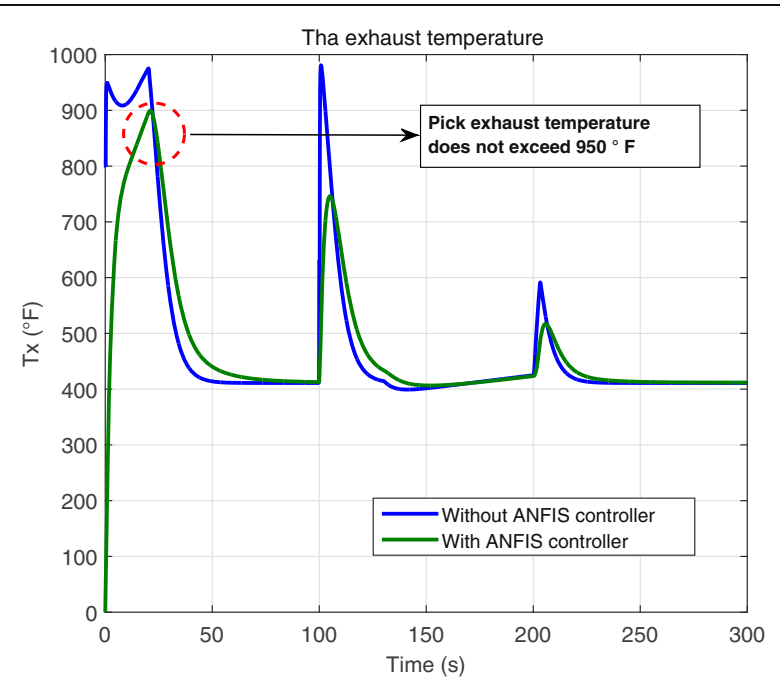

Fig. 22 Exhaust temperature of the gas turbine

at the reference speed, as shown in Fig. 20. However, due to this sudden perturbation the exhaust temperature rapidly increases as shown in Fig. 19. To clarify the main role of the controller used here, the exhaust temperature dynamics are presented both with and without the use of the controller. It can be seen that the difference is very clear when the exhaust temperature increases sharply. Indeed, the level exceeds the maximum allowed level of $960 \mathrm{~F}$ very rapidly to reach a huge overshoot value of $1160 \mathrm{~F}$ which can cause damage to the whole system. However, when the controller is used, the increase in exhaust temperature happens only slowly and never reaches the maximum limit, for a safe operation.

The second factor here is the linear speed decrease after $t=130 \mathrm{~s}$ representing a very soft braking of the turbine. In this case Figs. 18 and 19 show that the controller can achieve a very accurate and rapidly compensating control of both speed and exhaust temperature. At the same time, as shown in Fig. 20, torque dynamics respond well. We can conclude that, as long as the choice of PID parameters remains adequately accurate things are well even though the PID controller cannot support the proper control of gas turbine parameters over a wide range.

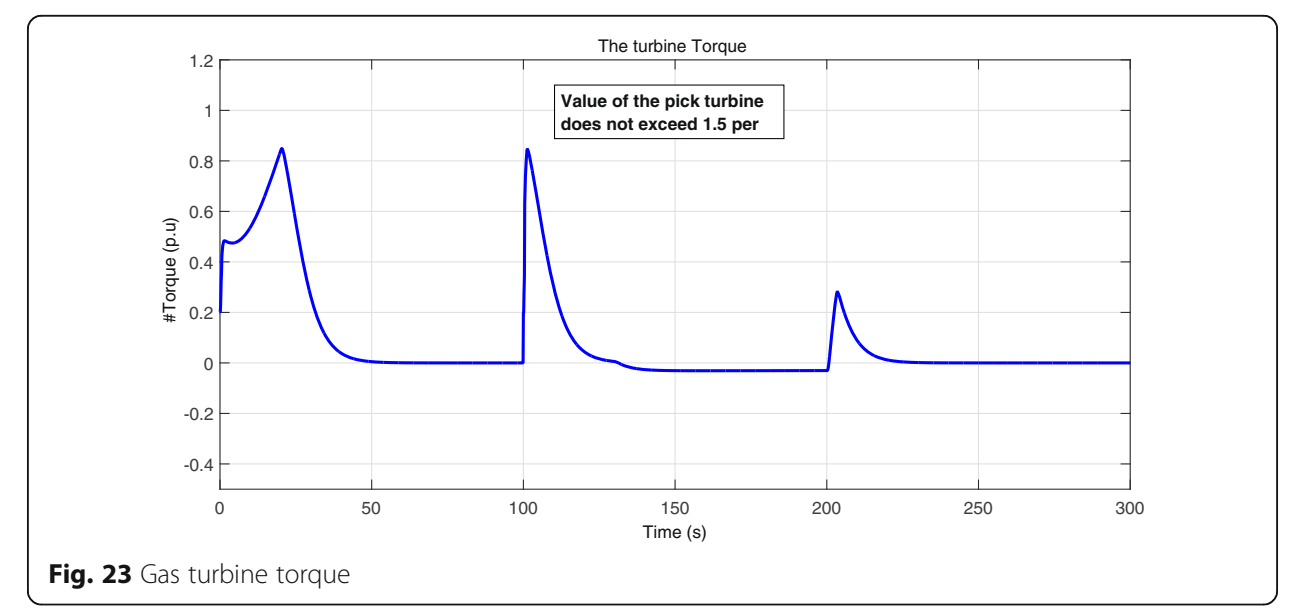


The proposed controller based on ANFIS approach

In order to validate the improved performance of the proposed ANFIS controller over the classical PID control, we performed a simulation test in which the same conditions as described in Section 3.2 were implemented. The results obtained are presented in Figs. 21, 22 , and 23. It can be seen that the ANFIS controller eliminates the three parametric peaks in the speed, the exhaust temperature, and the torque at start-up, avoiding the turbine damage risk associated with the classical PID controller. In particular, Fig. 23 shows a reduction in torque peak to about half the previous PID peak. On the other hand, controller performance in ensuring stability of speed and exhaust temperature is very satisfactory in that disturbances caused either by load change or speed reference change are rapidly brought under control, allowing speed and exhaust temperatures to rejoin their respective references within a very short time without substantial overshoot values. In conclusion, we can report that the proposed ANFIS controller allows the smooth control of complex gas turbines even under parameter variation.

\section{Conclusion}

The present work deals with the use of a Neuro-Fuzzy Adaptive Inference System (ANFIS) controller designed to ensure adequate control of speed and exhaust temperature for a Heavy Duty Gas Turbine (HDGT) based on Rowen Model equations. The results obtained clearly demonstrate the high performance of the proposed controller and its validity under varying operating conditions, in particular in comparison with the classical PID controller. In future work, more control parameters and different new constraints could be added to the study.

\section{Acknowledgements}

We would like to express our gratitude and acknowledgements to the staff of the Applied Automation and Industrial Diagnostics Laboratory of the University of Djelfa for his endless guidance and encouragement during the realization of this work.

Funding

This work is carried out by the Automation and Industrial Diagnostics Laboratory of the University of Djelfa, Algeria.

Authors' contributions

All authors read and approved the final manuscript.

\section{Competing interests}

This work proposes the integration of the artificial intelligence tools based on adaptive neuro-fuzzy inference system to ensure the heavy duty gas turbine monitoring, this fuzzy approach has the advantage of no need to the use of the analytical models to control the speed and the exhaust temperature in this equipment and make the gas turbine performance monitoring improved. This fuzzy method proposed in this paper permits based on the obtained gas turbine data to obtain information on system status, which will be useful for real time supervision.

\section{Publisher's Note}

Springer Nature remains neutral with regard to jurisdictional claims in published maps and institutional affiliations.

\section{Author details}

${ }^{1}$ Applied Automation and Industrial Diagnostics Laboratory, Faculty of Science and Technology, University of Djelfa, 17000 Djelfa, DZ, Algeria. ${ }^{2}$ Faculty of Science and Technology, University of Médéa, 26000 Médéa, Algeria.

${ }^{3}$ Aeronautical Aerospace Automotive Railway Engineering School, ESTACA, Paris, France.

Received: 2 July 2016 Accepted: 5 October 2017

Published online: 17 October 2017

\section{References}

1. A Benyounes, A Hafaifa and M Guemana, (2016) Fuzzy logic addresses turbine vibration on Algerian gas line. Oil Gas J 114(1):22-28. http://www.ogj.com/articles/print/volume-114/issue-1/transportation/fuzzy-logic-addressesturbine-vibration-on-algerian-gas-line.html 
2. A Benyounes, A Hafaifa, A Kouzoul and M Guemana (2016) Gas turbine modeling using adaptive fuzzy neural network approach based on measured data classification. Mathematics-in-Industry, Case Studies, vol.7, no.4, Springer DOI https://doi.org/10.1186/s40929-016-0006-3

3. Balamurugan S, Janarthanan N, Vijaya Chandrakala KRM (2016) Small and large signal modeling of heavy duty gas turbine plant for load frequency control. Int J Electr Power Energy Syst 79:84-88

4. Asgari $H$, Chen $X Q$, Morini M, Pinelli M, Sainudiin R (2016) Pier Ruggero Spina, Mauro Venturini, NARX models for simulation of the start-up operation of a single-shaft gas turbine. Appl Therm Eng 93:368-376

5. Zaidan MA, Mills AR, Harrison RF, Fleming PJ (2016) Gas turbine engine prognostics using Bayesian hierarchical models: a variational approach. Mech Syst Signal Process 70-71:120-140

6. Jang JSR ANFIS: adaptive-network-based fuzzy inference system. IEEE Trans Systems Man Cybernetics 23(3):665-685

7. Nikpey H, Assadi M, Breuhaus P, Mørkved PT (2014) Experimental evaluation and ANN modeling of a recuperative micro gas turbine burning mixtures of natural gas and biogas. Appl Energy 117:30-41

8. Onabanjo T, Di Lorenzo G, Goodger E, Somorin Y (2016) Modelling of microbial fuel degradation in liquid fuels for a gas turbine engine application. Int Biodeterior Biodegrad 109:191-201

9. Hafaifa A, Guemana M, Daoudi A (2015) Vibration supervision in gas turbine based on parity space approach to increasing efficiency. J Vib Control 21:1622-1632

10. B Djaidir, A Hafaifa and K Abdallah (2015) Performance control of gas turbines. Turbomachinery Int J. https:// turbomachinerymag.com/category/magazine/

11. Djaidir B, Hafaifa A, Abdallaha K (2015) Monitoring gas turbines using Speedtronic mark VI control systems. Pipeline Gas J 242(10):48-86

12. Saadat B, Hafaifa A, Guemana M (2016) Vibration analysis and measurement based on defect signal evaluation: gas turbine investigation. J Adv Res Sci Technol 3(1):271-280

13. Mohamed Ben Rahmoune, Ahmed Hafaifa and Guemana Mouloud (2015) Vibration modeling improves pipeline performance, costs. Oil \& Gas J 113(3):98-100. http://www.ogj.com/articles/print/volume-113/issue-3.html

14. Mohamed Ben Rahmoune, Ahmed Hafaifa, Mouloud Guemana, Fault diagnosis in gas turbine based on neural networks: Vibrations speed application. Proceedings of the International Conference on Acoustics and Vibration ATAVI'16, March 21-23, 2016, Hammamet -Tunisia

15. Nadji Hadroug, Ahmed Hafaifa and Attia Daoudi, Valve actuator fault classification based on fuzzy system using the DAMADICS model. Proceedings of the 1st International Conference on Applied Automation and Industrial Diagnostics (ICAAID 2015), Djelfa on 29-30 march 2015, Algeria

16. Hadroug N, Hafaifa A, Kouzou A, Chaibet A (2016) Faults detection in gas turbine using hybrid adaptive network based fuzzy inference systems to controlling there dynamic behavior. DIAGNOSTYKA J Polish Soc Technical Diagnostics (PSTD) 17(4):3-17

17. Hadroug N, Hafaifa A, Abdellah K, Chaibet A (2017) Dynamic model linearization of two shafts gas turbine via their input / output data around the equilibrium points. Ener Elsevier J 120:488-497

18. M. Reza Bank Tavakoli, B. Vahidi " An Educational Guide to Extract the Parameters of Heavy Duty Gas Turbines Model in Dynamic Studies Based on Operational Data" IEEE transactions on power systems, vol. 24, no. 3, august 2009

19. Zhu Q, Luo X, Zhang B, Chen Y, Mo S (2016) Mathematical modeling, validation, and operation optimization of an industrial complex steam turbine network-methodology and application. Energy 97:191-213

20. Effiom SO, Abam Fl, Ohunakin OS (2015) Performance modeling of industrial gas turbines with inlet air filtration system. Case Studies Thermal Engineering 5:160-167

21. Liang J, Qiu Y, Zhao M, Kang S, Lu H (2015) The modeling and numerical simulations of wind turbine generation system with free vortex method and simulink. Energy Convers Manag 103:762-777

22. William I. Rowen, "Simplified mathematical representations of heavy-duty gas turbines," Eng. Power, oct 1983

\section{Submit your manuscript to a SpringerOpen ${ }^{\circ}$ journal and benefit from:}

- Convenient online submission

- Rigorous peer review

- Open access: articles freely available online

- High visibility within the field

- Retaining the copyright to your article

Submit your next manuscript at $>$ springeropen.com 